\title{
Cerium doped copper/ZSM-5 catalysts used for the selective catalytic reduction of nitrogen oxide with ammonia
}

\author{
Baojuan Dou ${ }^{\mathrm{a}}$, Gang Lv ${ }^{\mathrm{b}}$, Chang Wang ${ }^{\mathrm{a}}$, Qinglan $\mathrm{Hao}^{\mathrm{a}, *}$, KwanSan Hui ${ }^{\mathrm{c}, ~ * *}$ \\ ${ }^{a}$ College of Marine Science \& Engineering, Tianjin University of Science \& \\ Technology, 13 St. TEDA, Tianjin, 300457,PR China \\ ${ }^{b}$ State Key Laboratory of Engines, Tianjin University, Weijin Road 92, Tianjin \\ 300072, PR China \\ ${ }^{c}$ Department of Mechanical Convergence Engineering, Hanyang University, 17 Haen \\ gdang-dong, Seongdong-gu, Seoul 133-791, Republic of Korea
}

\begin{abstract}
:
The CuCe/ZSM-5 catalysts with different cerium loadings $(0,0.5,1.0,1.5$ and 2.0 wt.\%) was investigated to evaluate the correlation between structural characteristics and catalytic performance for the selective catalytic reduction (SCR) of $\mathrm{NO}$ by $\mathrm{NH}_{3}$. It was found that the addition of cerium increased copper dispersion and prevented its crystallization. According to the results of X-ray photoelectron spectroscopy (XPS) and temperature-programmed reduction by hydrogen $\left(\mathrm{H}_{2}-\mathrm{TPR}\right)$, copper species were enriched on the ZSM-5 grain surfaces and part of copper ions was incorporated into the cerium lattice. Addition of cerium improved the redox properties of the CuCe/ZSM-5 catalysts, owing to the higher valence of copper and mobility of lattice oxygen than those of $\mathrm{Cu} / \mathrm{ZSM}-5$ catalyst. Hence the introduction of
\end{abstract}

\footnotetext{
${ }^{*}$ Corresponding author. Tel.: +86-22-60601278; Fax.: +86-22-60600320

E-mail address: haoqinglan@ tust.edu.cn

** Corresponding author. Tel.: +822 2220 0441; fax: +822 22202299 (K. Hui)E -mail address: kshui@hanyang.ac.kr (K. Hui)
} 
cerium in Cu/ZSM-5 improved significantly NO conversion. On the one hand, the cerium introduction into $\mathrm{Cu}-\mathrm{Z}$ enhances their low-temperature activities. 95\% NO conversion is reached around $197{ }^{\circ} \mathrm{C}$ for $\mathrm{Cu}-\mathrm{Z}$ while the corresponding temperature value decreases to $148{ }^{\circ} \mathrm{C}$ for $\mathrm{CuCe} 4-\mathrm{Z}$. On the other hand, the temperature range of efficient NO reduction (95\%) also extends to higher temperature when the cerium are added to $\mathrm{Cu} / \mathrm{ZSM}-5$. Among the Cu-Ce/ZSM-5 catalysts tested, the CuCe4-Z sample exhibits the highest catalytic activity with the temperature range for $90 \% \mathrm{NO}$ removal of $148-427^{\circ} \mathrm{C}$.

Keywords: Selective catalytic reduction; CuCe/ZSM-5 catalyst; Nitrogen oxide; Ammonia

\section{Introduction}

Nitrogen oxides $\left(\mathrm{NO}_{\mathrm{x}}\right)$ are hazardous to human health, contributing to seriously environmental problems. Selective catalytic reduction (SCR) of $\mathrm{NO}_{x}$ by $\mathrm{NH}_{3}$ is an efficient technology for controlling $\mathrm{NO}_{\mathrm{x}}$ emissions [1]. Ever since Iwamoto et al [2] reported that the Cu-ZSM-5 catalyst showed high activity of selective catalytic reduction of $\mathrm{NO}_{x}$, much work has been performed to explore the catalytic properties of those catalysts, especially for on-road applications $[3,4]$. The utility of ZSM-5 as catalyst supports derives significantly from their remarkable ion-exchange capacity [5]. For the reaction mechanism over copper exchanged zeolites, different copper species which is active for SCR reaction were identified in $\mathrm{Cu} / \mathrm{ZSM}-5$, mainly including isolated ions either in framework positions or in cationic positions in the 
zeolite channels, copper clusters in extra-framework positions, copper oxide located at the surface of the zeolite crystal [6,7]. When the temperature increases, these copper species exhibit the catalytic activity with turnover frequency decreasing in the order: isolated copper ions > copper clusters > copper oxide. Hence the Cu/ZSM-5 exhibits a wider operation window than commercial $\mathrm{V}_{2} \mathrm{O}_{5}-\mathrm{WO}_{3} / \mathrm{TiO}_{2}$ catalysts.

It is well known that the key factors determining the activity and selectivity of supported catalysts are the nature and dispersion of copper species, which depend approximately on the aluminum content in the framework and the copper loading ratio $[8,9]$. Many researches demonstrated that the most active catalysts tend to have the lowest $\mathrm{Si} / \mathrm{Al}$ atomic ratio because only copper ions close to framework $\mathrm{AlO}_{4}^{-}$are active in the decomposition of $\mathrm{NO}$ into $\mathrm{N}_{2}$ [10-12]. Unfortunately, too much aluminum anchored in the framework of ZSM-5 led to marked decrease in hydrothermal stability. The catalytic activity of Cu/ZSM-5 increases with enhancing copper content, reaching a maximum of $\mathrm{NO}_{x}$ conversion, and then decreases at higher contents. The reason for activity saturation is attributed to the grains of copper oxides growing up at high copper content because they promote inevitably the reductant oxidation in the presence of oxygen $[13,14]$. Considering the exhaust temperatures of automotives often varying in a wide range from $150{ }^{\circ} \mathrm{C}$ during a cold start to $600{ }^{\circ} \mathrm{C}$ for top-load operation, the existing active window of existing $\mathrm{Cu} / \mathrm{ZSM}-5$ is still unable to meet the requirement of various running mode of diesel engines.

To further enlarge the temperature window of application, a second metal is often introduced into $\mathrm{Cu} / \mathrm{ZSM}-5$ as additives. The combination and interaction between two 
metal elements significantly influence its bulk and surface physiochemical structure $[15,16]$. Ceria has been employed as a promoter for metal-containing ZSM-5 catalysts and its wide application is attributed to some special properties, such as: (1) the redox couple between the trivalent and tetravalent oxidation states of the ceria ions that allow easy oxygen exchange with the medium; (2) formation of labile oxygen vacancies and oxide ion storage; (3) to increase the dispersion and stability of the active form of the metal by strong metal-support interaction $[17,18]$. Sowade et al. [19] believed that In/ZSM-5 catalysts for the SCR of NO by methane are effectively promoted by extra-zeolite $\mathrm{CeO}_{2}$. The $\mathrm{CeO}_{2}$ is beneficial to catalyzing $\mathrm{NO}$ oxidation to provide a rich NO supply and acts independently from the other catalyst components. Similarly, Qi et al. [20] confirmed that ceria could promote the oxidization of NO to $\mathrm{NO}_{2}$, thus increasing the catalyst activity for SCR of $\mathrm{NO}$ with $\mathrm{NH}_{3}$. Carja et al. [21] synthesized MnCe/ZSM-5 catalyst by an aqueous phase method which exhibited a broad temperature window $\left(244-550{ }^{\circ} \mathrm{C}\right)$ for high $\mathrm{NO}$ conversions $(75-100 \%)$ even in the presence of $\mathrm{H}_{2} \mathrm{O}$ and $\mathrm{SO}_{2}$.

Herein, more attentions were focused on $\mathrm{CuO}_{x}-\mathrm{CeO}_{2}$ since its favorable properties in catalytic oxidation reactions, such as diesel soot, [22] volatile organic compounds [23] and carbon monoxide [24] etc. The reaction path follows a rodox mechanism, involving the change of the oxidation state of both copper $\left(\mathrm{Cu}^{2+} \leftrightarrow \mathrm{Cu}^{+}\right)$ and cerium $\left(\mathrm{Ce}^{4+} \leftrightarrow \mathrm{Ce}^{3+}\right)$. Up to data, however, few works are reported in the literature to evaluate SCR using $\mathrm{Cu}-\mathrm{Ce}$ based zeolites. The present study focused on the effects of ceria addition on the structures and copper species in copper-based 
ZSM-5 catalysts. The catalytic behavior of obtained materials was tested in selective catalytic reduction of $\mathrm{NO}_{x}$ using ammonia as reductant. The characterizations of the catalysts were analyzed through several characterization techniques, such as nitrogen sorption, X-ray powder diffractometer (XRD), scanning electron microscopy (SEM), and transmission electron microscopy (TEM), X-ray photoelectron spectroscopy (XPS), temperature-programmed desorption of $\mathrm{NH}_{3}$ measurement $\left(\mathrm{NH}_{3}-\mathrm{TPD}\right)$ and temperature-programmed reduction by hydrogen $\left(\mathrm{H}_{2}-\mathrm{TPR}\right)$.

\section{Experimental}

\subsection{Catalyst preparation}

H/ZSM-5 with an atomic $\mathrm{Si} / \mathrm{Al}$ ratio of 25 and crystallinity of $100 \%$ was supplied by Nankai University, Tianjin, P. R. China. The Cu/ZSM-5 and CuCe/ZSM-5 catalysts were prepared by a conventional ion-exchange technique [25]. An appropriate amount of copper and ceria nitrate were dissolved in deionized water and mixed with $0.5 \mathrm{~g}$ of $\mathrm{H} / \mathrm{ZSM}-5$. The resulting solution was stirred at $80{ }^{\circ} \mathrm{C}$ for $24 \mathrm{~h}$, at a $\mathrm{pH}$ of about 7.0. After being filtered and dried by evaporation, the sample was calcined in air at $600{ }^{\circ} \mathrm{C}$ for $4 \mathrm{~h}$. The copper and cerium concentrations of each calcined catalyst were determined by using a PerkinElmer AAnalyst 300 Atomic Absorption spectrometer (AAS). To evaluate the influence of cerium content on the $\mathrm{Cu} / \mathrm{ZSM}-5$ property of selective catalytic reduction of $\mathrm{NO}_{x}$, the copper content of the catalyst is set at $2.0 \mathrm{wt} . \%$, and the cerium contents are $0,0.5,1.0,1.5$ and $2.0 \mathrm{wt} . \%$, corresponding to $\mathrm{Cu}-\mathrm{Z}, \mathrm{CuCe} 1-\mathrm{Z}, \mathrm{CuCe} 2-\mathrm{Z}, \mathrm{CuCe} 3-\mathrm{Z}$ and $\mathrm{CuCe} 4-\mathrm{Z}$, respectively. 


\subsection{Characterization}

Nitrogen adsorption was measured with a NOVA 2000 gas sorption analyzer at liquid nitrogen temperature $\left(-196{ }^{\circ} \mathrm{C}\right)$. Prior to measurement, each sample was degassed under vacuum for $8 \mathrm{~h}$ at $300{ }^{\circ} \mathrm{C}$. The Brunauer-Emmett-Teller (BET) method was utilized to calculate the specific surface area using adsorption data acquired at a relative pressure $\left(\mathrm{P} / \mathrm{P}_{0}\right)$ range of $0.05-0.25$. The total pore volume was estimated from the amount of nitrogen adsorbed at a relative pressure of about 0.99 .

Pore size distribution curves were calculated using the Howarth-Kawazoe (HK) formalism for micropores and the Barret-Joyner-Halenda $(\mathrm{BJH})$ method from the adsorption branch for mesopores. The crystalline phase was determined by powder XRD using a Rigaku D/MAC/max 2500v/pc instrument with $\mathrm{Cu} \mathrm{K} \alpha$ radiation $(40 \mathrm{kV}$, $200 \mathrm{~mA}, \lambda=1.5418 \AA$ ). Diffractometer data were acquired with a step size of $0.02^{\circ}$ for $2 \theta$ values from $5-60^{\circ}$. TEM images of catalysts were observed with a Philips Tecnai $\mathrm{G}^{2} \mathrm{~F} 20$ microscope operating at $200 \mathrm{kV}$ coupled with an Oxford-1NCA EDX detector. Prior to TEM analysis, samples were dispersed in ethanol by sonication and deposited on a copper grid coated with a carbon film. XPS spectra were recorded on a Perkin-Elmer PHI-1600 ESCA spectrometer using Mg K $\alpha$ X-ray source. The binding energies were calibrated using $\mathrm{C} 1 \mathrm{~s}$ peak of contaminant carbon $(\mathrm{BE}=284.6 \mathrm{eV})$ as an internal standard. Temperature-programmed desorption of ammonia measurement ( $\mathrm{NH}_{3}$-TPD) test was performed in a Micromeritics Autochem 2920 II analyzer with the thermal conductivity detector (TCD). After being pretreated at $300{ }^{\circ} \mathrm{C}$ under flowing helium $\left(50 \mathrm{~mL} \mathrm{~min}^{-1}\right)$ for $1 \mathrm{~h}$, the powder sample $(100 \mathrm{mg})$ was cooled to 
$50{ }^{\circ} \mathrm{C}$, and then adsorbed to saturation by pulses of ammonia for $0.5 \mathrm{~h}$. Physically adsorbed ammonia on catalyst was removed by flushing the sample with helium (50 $\mathrm{mL} \min ^{-1}$ ) for $1 \mathrm{~h}$ at the adsorption temperature. Thermal desorption of ammonia was carried out in the temperature range of $50-600{ }^{\circ} \mathrm{C}$ at an increasing temperature rate of

$10{ }^{\circ} \mathrm{C} \min ^{-1}$. Temperature-programmed reductions with hydrogen $\left(\mathrm{H}_{2}\right.$-TPR) experiments were also performed with a Micromeritics Autochem 2920 II analyzer equipped with TCD. For the analysis, $100 \mathrm{mg}$ of sample was pre-treated in $20 \%$ oxygen at $600{ }^{\circ} \mathrm{C}$ for $30 \mathrm{~min}$. After cooling to $50{ }^{\circ} \mathrm{C}$, the $\mathrm{H}_{2}$-TPR was recorded in 10 vol. $\% \mathrm{H}_{2}$, with a heating rate of $10{ }^{\circ} \mathrm{C} \mathrm{min}^{-1}$ and a final temperature of $600{ }^{\circ} \mathrm{C}$.

\subsection{Catalytic activity testing}

Catalytic experiments were performed at atmospheric pressure in a flow-type apparatus designed for continuous operation. Before each test run, the catalyst powder was first pressed into a wafer and sieved into 20-40 meshes, and then $0.5 \mathrm{~g}$ of the catalyst was packed into a fixed-bed reactor made of a quartz tube with an internal diameter of $10 \mathrm{~mm}$. A K-type thermocouple was located inside the catalyst bed to monitor reaction temperature. The reaction was carried out across the temperature range $30-300{ }^{\circ} \mathrm{C}$, and the feed gas $\left(1000 \mathrm{ppm} \mathrm{NO}, 1000 \mathrm{ppm} \mathrm{NH}_{3}, 10 \% \mathrm{O}_{2}\right.$ and $\mathrm{N}_{2}$ to balance; space velocity (SV) of $15,000 \mathrm{~h}^{-1}$ ) was metered using calibrated electronic mass flow controllers. The concentration of $\mathrm{NO}, \mathrm{NO}_{2}, \mathrm{~N}_{2} \mathrm{O}$ and $\mathrm{NH}_{3}$ were monitored by using the on-line quadrupole mass spectrometer (OmniStar 200). 


\section{Results and discussion}

\subsection{Structure and morphology}

Fig. 1 shows the nitrogen adsorption-desorption isotherms for pure ZSM-5 and CuCe/ZSM-5 catalysts. According to the IUPAC classification, the shape of the adsorption isotherm curves for all the samples can be considered as a combination of type I and type IV, indicating the presence of microporous and slit shaped pores. The shape of adsorption-desorption isotherm remains the same as those before modification of ZSM-5 implying the modification does not change the pore shapes of the ZSM-5. As can be seen in Table 1, doping ZSM-5 with copper and cerium leads to a slightly decrease in BET surface area and micropore volume, from $380 \mathrm{~m}^{2} \mathrm{~g}^{-1}$ and $0.14 \mathrm{~cm}^{3} \mathrm{~g}^{-1}$ respectively for ZSM-5 to $318 \mathrm{~m}^{2} \mathrm{~g}^{-1}$ and $0.13 \mathrm{~cm}^{3} \mathrm{~g}^{-1}$ respectively for CuCe4-Z. This can be explained by the fact that copper and cerium species cover the external surface of ZSM-5, blocking a number of zeolite channels, and impeding entry of $\mathrm{N}_{2}$ into the pores.

XRD patterns of the pure ZSM-5, Cu-Z and CuCe/ZSM-5 catalysts are depicted in Fig. 2. The inherent MFI structure of ZSM-5 was observed $\left(2 \theta=7.8^{\circ}, 8.7^{\circ}, 24.5^{\circ}\right.$, $\left.24.9^{\circ}, \mathrm{PDF}=44-003\right)$ which suggests that the catalysts still maintain the well-ordered microstructure of ZSM-5 after the copper and cerium additions. However, the intensity of the ZSM-5 principal diffraction peaks decreased to a certain extent after the copper and cerium incorporation, probably owing to the higher absorption coefficient of metal compounds for X-ray radiation [26]. No diffraction peaks derived from metal or metal oxide clusters are observed for $\mathrm{Cu}-\mathrm{Z}, \mathrm{CuCe} 1-\mathrm{Z}, \mathrm{CuCe} 2-\mathrm{Z}$ and 
CuCe3-Z, suggesting that the species are well dispersed as amorphous metal species, or aggregated into mini-crystals that are too small to be detected by XRD [27]. With increasing the cerium content to $2.0 \mathrm{wt} . \%$, the peak of $\mathrm{CeO}_{2}$ are observed for CuCe4-Z $\left(2 \theta=28.2^{\circ}, \quad P D F=34-0394\right)$, which is explained by the fact that the extra-framework cerium is prone to agglomerate into cerium oxides clusters.

In order to gain further insight into the distribution of copper and cerium crystallites, the samples are characterized by TEM experiments. A typical bright field TEM image of pure ZSM-5 catalyst is shown in Fig. 3A. The sample is comprised of crystalline ZSM-5 particles, which are dispersed on the amorphous silica-alumina matrix and exhibit characteristic diffraction contrast. It can be seen that a relatively homogeneous distribution of copper particles are obtained over the $\mathrm{Cu}-\mathrm{Z}$ catalyst (Fig. 3B). The homogeneous distribution observed is agreement with those of XRD. The image in Fig. 3C reveals that the cerium added to the support is preferentially located at the external surface of the ZSM-5 zeolite. The fine particles are relatively spherical in shape and each particle is found to be an aggregate of nano-crystallites.

\subsection{XPS analysis}

The chemical states and surface proportions of elements for the catalysts were characterized by X-ray photoemission spectroscopy. Fig. 4 shows the XPS spectra of $\mathrm{Cu} 2 \mathrm{p}$. A low intensity of the shake-up satellite peak in the range of 938-945 eV confirms the existence of $\mathrm{Cu}^{2+}$ in the $\mathrm{Cu}-\mathrm{Z}$ and $\mathrm{CuCe}-\mathrm{Z}$ catalysts. As a consequence, peak deconvolution and fitting to experimental data show that the experimental $\mathrm{Cu}$ 
$2 \mathrm{p}_{3 / 2}$ peak could be fitted well by having two peaks corresponding to the chemical states $\mathrm{Cu}^{2+}$ at $934.3 \mathrm{eV}$ of $2 \mathrm{p}_{3 / 2}$ and $\mathrm{Cu}^{+}$at $933.0 \mathrm{eV}$ of $2 \mathrm{p}_{3 / 2}$. It can be seem from Fig. 4 that both charge states $1+$ and $2+$ are present in $\mathrm{Cu}-\mathrm{Z}$ and $\mathrm{CuCe}-\mathrm{Z}$ catalysts.

Fig. 5 displays the Ce $3 d$ XPS spectrum of the CuCe4-Z sample. The Ce $3 d$ spectra is complicated and can be individually deconvoluted into $3 \mathrm{~d}_{5 / 2}$ and $3 \mathrm{~d}_{3 / 2}$ spin-orbit components (labeled as $v$ and $u$, respectively) describing the $\mathrm{Ce}^{4+} \leftrightarrow \mathrm{Ce}^{3+}$ electronic transitions [28]. The four intense components $v(\mathrm{BE} \sim 882.5 \mathrm{eV}), u$ (BE 900.9 eV), $v^{\prime \prime \prime}(\mathrm{BE} \sim 898.2 \mathrm{eV}), u^{\prime \prime \prime}(\mathrm{BE} \sim 917.1 \mathrm{eV})$ as well as the two weaker components $v^{\prime \prime}(\mathrm{BE} \sim 889.4 \mathrm{eV})$ and $u^{\prime \prime}\left(\mathrm{BE}\right.$ 908.2 eV) can be attributed to $\mathrm{Ce}^{4+}$ cations. With respect to the $\mathrm{Ce}^{3+}$ cations, the $v^{\prime}(\mathrm{BE} \sim 885.6 \mathrm{eV})$ and $u^{\prime}(\mathrm{BE} \sim 903.7 \mathrm{eV})$ components are noticeably weaker than those for the $\mathrm{Ce}^{4+}$ cations [29-31]. Hence both $\mathrm{Ce}^{3+}$ and $\mathrm{Ce}^{4+}$ cations coexist in the $\mathrm{CuCe}-\mathrm{Z}$ catalysts.

Curve-fitting procedures were applied to the $\mathrm{O}$ 1s region, as shown in Fig. 6. The O 1s XPS spectrum of $\mathrm{Cu}-\mathrm{Z}$ shows a strong peak at $531.8 \mathrm{eV}$, which represents large numbers of lattice oxygen from the ZSM-5 zeolite structure, together with relatively small amounts of chemisorbed oxygen and weakly bonded oxygen species. Field investigations have shown that $\mathrm{Ce}^{3+}$ could create a charge imbalance, vacancies and unsaturated chemical bonds on the sample surface, for which more chemisorbed oxygen or/and weakly bonded oxygen species would be brought [32]. These oxygen species play an important role in oxidation reaction [33]. The O 1s XPS spectra of $\mathrm{CuCe}-\mathrm{Z}$ catalysts show two primary peaks. Similarly to that of the $\mathrm{Cu}-\mathrm{Z}$, the peak at a higher binding energy of $531.8 \mathrm{eV}$ may be assigned to regular lattice oxygen from the 
ZSM-5 zeolite structure $(\mathrm{Oz})$, chemisorbed oxygen and weakly bonded oxygen species, while the shoulder peak at about $529.7 \mathrm{eV}$ corresponds to lattice oxygen from copper and cerium oxides (Oo).

Table 2 shows that the surface $\mathrm{Cu} / \mathrm{Si}, \mathrm{Ce} / \mathrm{Si}, \mathrm{Cu}^{+} / \mathrm{Cu}^{2+}, \mathrm{Ce}^{3+} / \mathrm{Ce}^{4+}$ and $\mathrm{Oo} / \mathrm{Oz}$ atomic ratios over the catalysts. It can be confirmed from the results that the copper and cerium appear to enrich on the surface of ZSM-5 grains, since the $\mathrm{Cu} / \mathrm{Si}$ and $\mathrm{Ce} / \mathrm{Si}$ atomic ratios detected by XPS increase monotonously with the cerium content increasing, and are considerably large than those values obtained from AAS. Given that the copper content is set at $2.0 \mathrm{wt} . \%$ during the catalyst preparation, the $\mathrm{Cu} / \mathrm{Si}$ atomic ratios also exhibit an increasing tread with cerium content, indicating that the enriched copper species are perhaps interacting on cerium and are preferentially cover the cerium phases.

The $\mathrm{Cu}^{+} / \mathrm{Cu}^{2+}, \mathrm{Ce}^{3+} / \mathrm{Ce}^{4+}$ and $\mathrm{Oo} / \mathrm{Oz}$ surface atomic ratios calculated according to relative peak areas from XPS spectra are also listed in Table 2. In particular, the concentration of $\mathrm{Ce}^{3+}$ and $\mathrm{Ce}^{4+}$ cations in $\mathrm{CuCe}-\mathrm{Z}$ catalysts can be estimated as Eqs. (1) and (2), [34] where the $\left[\mathrm{Ce}^{3+}\right]$ and $\left[\mathrm{Ce}^{4+}\right]$ stand for the sums of the integrated peak areas related to their XPS signals respectively:

$$
\begin{aligned}
& {\left[\mathrm{Ce}^{3+}\right]=v^{\prime}+u^{\prime}} \\
& {\left[\mathrm{Ce}^{4+}\right]=v+v^{\prime \prime}+v^{\prime \prime \prime}+u+u^{\prime \prime}+u^{\prime \prime \prime}}
\end{aligned}
$$

As the cerium content increases, the $\mathrm{Cu}^{+} / \mathrm{Cu}^{2+}$ and $\mathrm{Ce}^{3+} / \mathrm{Ce}^{4+}$ ratios are reduced from $1.142(\mathrm{Cu}-\mathrm{Z})$ to $0.816(\mathrm{CuCe} 4-\mathrm{Z})$ and from $0.279(\mathrm{CuCe} 1-\mathrm{Z})$ to $0.232(\mathrm{CuCe} 4-\mathrm{Z})$, respectively. Moreover, the $\mathrm{Oo} / \mathrm{Oz}$ surface atomic ratio exhibits an increasing trend 
with cerium content. Combined with the XRD results, the overfull cerium enriched on the ZSM-5 support is easily aggregated and sintered to formed bulk $\mathrm{CeO}_{2}$ during the calcination process. As such, the decrease of $\mathrm{Ce}^{3+} / \mathrm{Ce}^{4+}$ ratio is probably caused by the formation of the ceria. Concerning the $\mathrm{Cu} 2 \mathrm{p}$ spectra, most copper initially present in these samples is in a +2 oxidation state and small amount in $a+1$ oxidation state for the $\mathrm{CuCe}-\mathrm{Z}$ catalysts, located at 934.3 and $933.0 \mathrm{eV}$, respectively. The copper and cerium interaction acts as a reservoir of finely dispersed copper species ensuring high catalytic activity [35]. We propose that part of copper ions have probably entered the ceria lattice, which lead to form low concentration of $\mathrm{Ce}^{3+}$ defects.

\subsection{Temperature-programmed desorption of ammonia}

Fig. 7 shows the $\mathrm{NH}_{3}-\mathrm{TPD}$ results obtained for pure $\mathrm{ZSM}-5, \mathrm{Cu}-\mathrm{Z}$ and $\mathrm{CuCe}-\mathrm{Z}$ samples. In the case of the parent $\mathrm{H}-\mathrm{ZSM}-5$, three $\mathrm{NH}_{3}$ desorption peaks at maximum temperatures of about 110,170 and $320{ }^{\circ} \mathrm{C}$ are clearly observed. Here, the peaks located at 110 and $170{ }^{\circ} \mathrm{C}$ can be reasonably ascribed to weak acidic sites, arising from $\mathrm{NH}_{3}$ physisorbed on $\mathrm{Si}-\mathrm{OH}$ or from non-zeolitic impurities. The peak located at $320{ }^{\circ} \mathrm{C}$ can be ascribed to the strong acidic sites, assigned to $\mathrm{NH}_{3}$ bound to strong acid sites. Upon introduction of copper and cerium, the maximum temperatures of $\alpha$ and $\beta$ peaks are slightly increased, indicative of a slight increase in the intensity of the weak acidic sites, whereas the $\gamma$ peaks decrease considerably. The nitrogen sorption results (Fig. 1 and Table 1) have confirmed that the increase of the cerium loading leads to the blockage of partial micropores and decrease of BET surface area. Thus, the $\gamma$ 
desorption peak vanishes when the copper is introduced, indicating that some copper ions are exchanged on the acid sites or partial copper species enriched on the ZSM-5 surface covers acid sites. With the cerium content increasing, some new $\mathrm{NH}_{3}$ desorption peaks appear at the high temperature $>250{ }^{\circ} \mathrm{C}$ for the $\mathrm{CuCe}-\mathrm{Z}$ samples, indicating the formation of stronger acid sites. It is reasonable to conclude that the ammonia chemisorption at temperatures higher than $250{ }^{\circ} \mathrm{C}$ is mainly due to cerium oxide nanoclusters. Combined with the finding from TEM and XPS that the cerium is enriched on the surface of ZSM-5 grains, there should be a correlation between the quantity of chemisorbed ammonia and number of cerium ions exposed on the surface of the active phase. Likely, ammonia molecules are bonded to cerium by donor-acceptor bond, which is formed by attaching the free electron pair of ammonia into unoccupied d-orbitals of cerium.

\subsection{Temperature-programmed reduction of hydrogen}

Temperature-programmed reduction experiments were carried out to get further insights into copper species and their redox properties. The obtained profiles are shown in Fig. 8 and the results are listed in Table 3. The nature of the copper species present in the ZSM-5 zeolite is commonly discussed on basis of the position of the $\mathrm{H}_{2}$ consumption peaks and the peak areas. For the pure ZSM-5 sample, there is no obvious reduction peak during the $\mathrm{H}_{2}$ reduction process. TPR profile of the $\mathrm{Cu}-\mathrm{Z}$ sample exhibits two reduction peaks at 227 and $280{ }^{\circ} \mathrm{C}$, respectively. The $\alpha$ peak at $227{ }^{\circ} \mathrm{C}$ is attributed to the reduction of copper species dispersed on the ZSM-5 
support, while the $\beta$ peak at $280{ }^{\circ} \mathrm{C}$ corresponds to the reduction of the copper oxides adhering to the external surface of ZSM-5 crystallites. These oxides aggregate to form crystallites that are too small to be detected by XRD. Upon addition of cerium, TPR curves of CuCe-Z samples exhibit four reduction peaks at about 200, 230, 270 and $380{ }^{\circ} \mathrm{C}$. Similar to the $\mathrm{Cu}-\mathrm{Z}$ sample, the $\alpha\left(222^{\circ} \mathrm{C}\right)$ and $\beta\left(276^{\circ} \mathrm{C}\right)$ peaks of $\mathrm{CuCe}-\mathrm{Z}$ samples are assigned to the dispersed copper clusters and copper oxides, respectively. As shown in Table 3 , the $\mathrm{H}_{2}$ consumption for the $\alpha$ peaks are in the range of $25-27 \mu \mathrm{mol} \mathrm{H}_{2} \mathrm{~g}^{-1}$ with the cerium content increasing from $0(\mathrm{Cu}-\mathrm{Z})$ to 1.0 wt.\% (CuCe2-Z). Significant increase of $\mathrm{H}_{2}$ consumption for the $\alpha$ peaks can be found when the cerium content is higher than 1.0 wt. $\%$, reaching $57 \mu \mathrm{mol} \mathrm{H} \mathrm{H}_{2} \mathrm{~g}^{-1}$ for CuCe3-Z and $64 \mu \mathrm{mol} \mathrm{H}_{2} \mathrm{~g}^{-1}$ for $\mathrm{CuCe} 4-\mathrm{Z}$, respectively. By contrast, the $\mathrm{H}_{2}$ consumption for the $\beta$ peaks decreases. These results indicate that the cerium introduction promotes the dispersion of copper species. Combined with the XPS results, it is reasonable to deduce that these copper species in proximity to the cerium phase are reduced more easily by hydrogen than those on the pure ZSM-5 support. After the cerium addition, the $\gamma$ and $\delta$ peaks appear for the $\mathrm{CuCe}-\mathrm{Z}$ samples. Possibly, some copper ions are incorporated into the vacant sites of the cerium oxides to form an oxygen-capped surface structure, although the solubility of copper into the ceria network is low. The formation of mixed oxides results in coordinative unsaturated species and thus increases oxygen mobility. Hence reduction is no longer confined to the surface of the material, but extends deep into its bulk, which may accelerate the reduction process and consume more hydrogen. Compared to the $\mathrm{Cu}-\mathrm{Z}$ sample loaded 
mono-metal, the samples modified by cerium-metal consumed more hydrogen during the reduction process (as shown in Table 3) and obtain the maximum of $202 \mu \mathrm{mol} \mathrm{H}_{2}$ $\mathrm{g}^{-1}$ for the $\mathrm{CuCe} 3-\mathrm{Z}$, which testify that more reduction species have been obtained for the $\mathrm{CuCe}-\mathrm{Z}$ samples than that of the $\mathrm{Cu}-\mathrm{Z}$.

\subsection{Catalytic activity tests}

Fig. 9 shows the NO conversion in the SCR reaction on the pure ZSM-5, Cu-Z and $\mathrm{CuCe}-\mathrm{Z}$ catalysts from 50 to $300{ }^{\circ} \mathrm{C}$. Pure ZSM-5 is inactive over the entire temperature range studied. The $\mathrm{Cu}-\mathrm{Z}$ and $\mathrm{CuCe}-\mathrm{Z}$ catalysts exhibit a similar trend of NO conversions, and more importantly the $\mathrm{CuCe}-\mathrm{Z}$ catalysts characterized by higher cerium content exhibit better catalytic performances. On the one hand, the cerium introduction into $\mathrm{Cu}-\mathrm{Z}$ enhances their low-temperature activities. The light-off temperature (10\% NO conversion) is reached at $103{ }^{\circ} \mathrm{C}$ for $\mathrm{Cu}-\mathrm{Z}$ while the value is shifted to $60{ }^{\circ} \mathrm{C}$ when the cerium content increases in $\mathrm{CuCe} 4-\mathrm{Z} .95 \% \mathrm{NO}$ conversion is reached around $197{ }^{\circ} \mathrm{C}$ for $\mathrm{Cu}-\mathrm{Z}$ while the corresponding temperature value decreases to $148^{\circ} \mathrm{C}$ for $\mathrm{CuCe} 4-\mathrm{Z}$. All the samples reach the full conversion above 205 ${ }^{\circ} \mathrm{C}$. On the other hand, when the cerium are added to $\mathrm{Cu} / \mathrm{ZSM}-5$, the temperature range of efficient NO reduction (95\%) also extends to higher temperature. Among the $\mathrm{Cu}-\mathrm{Ce} / \mathrm{ZSM}-5$ catalysts tested, the CuCe4-Z sample exhibits the highest catalytic activity with the temperature range for $90 \%$ NO removal of $148-427{ }^{\circ} \mathrm{C}$. The SCR process induced by all the catalysts produces $\mathrm{N}_{2} \mathrm{O}$ and $\mathrm{NO}_{2}$ as byproducts. In the whole range of this study, however, it can be observed that $\mathrm{N}_{2} \mathrm{O}$ and $\mathrm{NO}_{2}$ 
concentrations are below $10 \mathrm{ppm}$ on all the catalysts. In this case, the NO selectivity to $\mathrm{N}_{2}$ is close to $100 \%$.

It is widely accepted that in a typical heterogeneous catalytic reaction, the adsorption of reactants and the activation of adsorbed species are both required for the process to occur. the SCR process on $\mathrm{Cu}-\mathrm{Z}$ and $\mathrm{CuCe}-\mathrm{Z}$ catalysts involves three sequential reactions in the catalytic cycle [36]: (i) $\mathrm{Cu}^{+}$species are preferentially oxidized by $\mathrm{O}_{2}$ to form $\mathrm{Cu}^{2+}$ species; (ii) the oxygen in the atmosphere then reacts with $\mathrm{NO}$ to produce a surface nitrogen oxide intermediate bound to $\mathrm{Cu}^{2+}$, namely " $\mathrm{Cu}^{2+}-\mathrm{N}_{\mathrm{x}} \mathrm{O}$ " ; (iii) the resulting $\mathrm{Cu}^{2+}-\mathrm{N}_{\mathrm{x}} \mathrm{O}_{\mathrm{y}}$ active intermediate reacts with ammonia to yield $\mathrm{N}_{2}$ and $\mathrm{H}_{2} \mathrm{O}$, accompanied by the regeneration of $\mathrm{Cu}^{+}$. The $\mathrm{Cu}-\mathrm{Z}$ catalyst with outstanding activity is a good candidate for the selective catalytic reduction of NO by $\mathrm{NH}_{3}$. As expected, the introduction of cerium significant promotes the activity of $\mathrm{Cu}-\mathrm{Z}$, and the activity of catalyst increases with the increase of cerium content. According to the XRD results, the cerium addition has little influence on copper dispersion. A good dispersion of copper species, giving an intimate contact with the ZSM-5 support, leads to a stronger tendency for copper to be oxidized and thus stabilizes copper species against decomposition or reduction. The highly dispersed copper species are enriched on the surface of ZSM-5 grains. According to the TEM results, a fraction of the copper and cerium oxide clusters are probably located on the outer surfaces of ZSM-5 crystals. The XPS analysis also confirms that the ratios of $\mathrm{Cu} / \mathrm{Si}$ and $\mathrm{Ce} / \mathrm{Si}$ are higher than that from AAS results. The enrichment of copper species inclined to highly disperse on the catalyst surface provide better contact 
conditions for the NO conversion. The appropriate cerium addition enhances redox ability. According to the literature [37], the facile $\mathrm{Ce}^{4+} / \mathrm{Ce}^{3+}$ redox cycle can promote the transformation of $\mathrm{Cu}^{+}$to $\mathrm{Cu}^{2+}$ involving the following step: $\mathrm{Cu}^{2+}+\mathrm{Ce}^{3+} \leftrightarrow$ $\mathrm{Cu}^{+}+\mathrm{Ce}^{4+}$, and hence resulting in a higher content of $\mathrm{Cu}^{2+}$ species in the cerium-containing catalysts. Due to the existence of $\mathrm{Ce}^{3+} / \mathrm{Ce}^{4+}$ redox couple in cerium-containing catalysts, the coordinative unsaturates formed in the mixed oxides lead to the reduction no longer confined to the surface, but extended deep into the bulk of the material, which may accelerate the reduction process.

\section{Conclusion}

The present study focused on the effects of ceria addition on the structures and copper species in copper based ZSM-5 catalysts. The catalytic behavior of obtained catalysts was tested in selective catalytic reduction of $\mathrm{NO}_{x}$ using ammonia as reductant. It was found that the addition of cerium increased copper dispersion and prevented its crystallization. Copper species were enriched on the ZSM-5 grain surfaces and part of copper ions was incorporated into the cerium lattice. Moreover, Addition of cerium improved the redox properties of the CuCe/ZSM-5 catalysts, which arose from the higher valence of copper and mobility of lattice oxygen than those of Cu/ZSM-5 catalyst, which have been confirmed in the XPS and $\mathrm{H}_{2}$-TPR analysis. In this case, when the cerium are introduced into the Cu/ZSM-5, the temperature range of efficient NO reduction (95\%) extends to both lower and higher temperatures, i.e. the active window widens. Among the CuCe/ZSM-5 catalysts tested, the $\mathrm{CuCe} 4-\mathrm{Z}$ exhibits the highest catalytic activity with the temperature range of $95 \%$ 
NO removal of $148-427^{\circ} \mathrm{C}$.

\section{Acknowlegements}

This study was supported by the National Natural Science Foundation of China

(21307088) and the Tianjin Research Program of Application Foundation and Advanced Technology (10JCZDJC24900).

\section{References}

[1] H. Chang, L. Ma, S. Yang, J. Li, L. Chen, W. Wang, J. Hao, Comparison of preparation methods for ceria catalyst and the effect of surface and bulk sulfates on its activity toward $\mathrm{NH}_{3}-\mathrm{SCR}$, J. Hazard. Mater. 262 (2013) 782- 788.

[2] M. Iwamoto, H. Yahiro, Y. Mine, S. Kagawa, Excessively copper ion-exchanged ZSM-5 zeolites as highly active catalysts for direct decomposition of nitrogen monoxide, Chem. Lett. 18 (1989) 213-216.

[3] L. Olsson, H. Sjövall, R.J. Blint, A kinetic model for ammonia selective catalytic reduction over Cu-ZSM-5, Appl. Catal. B 81 (2008) 203-217.

[4] X.F. Yang, Z.1. Wu, M. Moses-Debusk, D.R. Mullins, S.M. Mahurin, R. A. Geiger, M. Kidder, C. K. Narula, Heterometal incorporation in metal-exchanged zeolites enables low-temperature catalytic activity of $\mathrm{NO}_{x}$ reduction, J. Phys. Chem. C 116 (2012) 23322-23331.

[5] B. Greenhalgh, M. Fee, J. Moir, R. Burich, J.P. Charland, M. Stanciulescu, DeNOx activity-TPD correlations of $\mathrm{NH}_{3}-\mathrm{SCR}$ catalysts, J. Mol. Catal. A 
333(2010) 121-127.

[6] Z. Chajar, M. Primet, H. Praliaud, M. Chevrier, C. Gauthier, F. Mathis, Nitrogen dioxide effect in the reduction of nitric oxide by propane in oxidizing atmosphere, Chem. Lett. 28 (1994) 33-40.

[7] M. Occhiuzzi, G. Fierro, G. Ferraris, G. Moretti, Unusual complete reduction of $\mathrm{Cu}^{2+}$ species in $\mathrm{Cu}-\mathrm{ZSM}-5$ zeolites under vacuum treatment at high temperature, Chem. Mater. 24 (2012) 2022-2031.

[8] J.H. Kwak, D. Tran, S. D. Burton, J. Szanyi, J.H. Lee, C.H.F. Peden, Effects of hydrothermal aging on $\mathrm{NH}_{3}$-SCR reaction over Cu/zeolites, J. Catal. 287(2012) 203-209.

[9] C. Torre-Abreu, M.F. Ribeiro, C. Henriques, G. Delahay, Characterisation of CuMFI catalysts by temperature programmed desorption of $\mathrm{NO}$ and temperature programmed reduction: Effect of the zeolite $\mathrm{Si} / \mathrm{Al}$ ratio and copper loading, Appl. Catal. B 12(1997) 249-262.

[10]R. Nedyalkova, C. Montreuil, C. Lambert, L. Olsson, Inter zeolite conversion of FAU type zeolite into CHA and its application in $\mathrm{NH}_{3}-\mathrm{SCR}$, Top. Catal. 56 (2013) $550-557$.

[11]G. Moretti, C. Dossi, A. Fusi, S. Recchia, R. Psaro, A comparison between $\mathrm{Cu}-\mathrm{ZSM}-5, \mathrm{Cu}-\mathrm{S}-1$ and $\mathrm{Cu}-\mathrm{mesoporous}^{-}$ilica-alumina as catalysts for $\mathrm{NO}$ decomposition, Appl. Catal. B 20(1999) 67-73.

[12]S. Dzwigaj, J. Janas, J. Gurgul, R.P. Socha, T. Shishido, M. Che, Do Cu(II) ions need $\mathrm{Al}$ atoms in their environment to make $\mathrm{CuSiBEA}$ active in the SCR of NO 
by ethanol or propane? A spectroscopy and catalysis study, Appl. Catal. B 85 (2009) 131-138.

[13]A. Boix, E.E. Mir, E.A. Lombardo, M.A. M.A. Bañares, R. Mariscal, J.L.G. Fierro, The nature of cobalt species in Co and $\mathrm{PtCoZSM}_{5}$ used for the SCR of $\mathrm{NO}_{x}$ with $\mathrm{CH}_{4}$, J. Catal. 217 (2003) 186-194.

[14]M.C. Campa, S. De Rossi, G. Ferraris, V. Indovina, Catalytic activity of Co-ZSM-5 for the abatement of $\mathrm{NO}_{x}$ with methane in the presence of oxygen, Appl. Catal. B 8 (1996) 315-331.

[15]F. Liu, H. He, Y. Ding, C. Zhang, Effect of manganese substitution on the structure and activity of iron titanate catalyst for the selective catalytic reduction of $\mathrm{NO}$ with $\mathrm{NH}_{3}$, Appl. Catal. B 93 (2009) 194-204.

[16]G. Picasso, M. Gutierrez, M.P. Pina, J. Herguido, Preparation and characterization of $\mathrm{Ce}-\mathrm{Zr}$ and $\mathrm{Ce}-\mathrm{Mn}$ based oxides for n-hexane combustion: Application to catalytic membrane reactors, Chem. Eng. J. 126 (2007) 119-130.

[17]L. Katta, P. Sudarsanam, G. Thrimurthulu, B.M. Reddy. Doped nanosized ceria solid solutions for low temperature soot oxidation: Zirconium versus lanthanum promoters, Appl. Catal. B 101 (2010) 101-108.

[18]O.H. Laguna, F. Romero Sarria, M.A. Centeno, J.A. Odriozola. Gold supported on metal-doped ceria catalysts $(\mathrm{M}=\mathrm{Zr}, \mathrm{Zn}$ and $\mathrm{Fe})$ for the preferential oxidation of CO (PROX), J. Catal. 276(2010) 360-370.

[19]T. Sowade, T. Liese, C. Schmidt, F.W. Schutze, X. Yu, H. Berndt, W. Grunert, Relations between structure and catalytic activity of Ce-In-ZSM-5 catalysts for 
the selective reduction of $\mathrm{NO}$ by methane: II. Interplay between the $\mathrm{CeO}_{2}$ promoter and different indium sites, J. Catal. 225(2004) 105-115.

[20]G. Qi, R.T. Yang, R. Chang, $\mathrm{MnO}_{\mathrm{x}}-\mathrm{CeO}_{2}$ mixed oxides prepared by co-precipitation for selective catalytic reduction of $\mathrm{NO}$ with $\mathrm{NH}_{3}$ at low temperatures, Appl. Catal. B 51(2004) 93-106.

[21]G. Carja, Y. Kameshima, K. Okada, C.D. Madhusoodana, Mn-Ce/ZSM5 as a new superior catalyst for NO reduction with $\mathrm{NH}_{3}$. Appl. Catal. B 73 (2007) 60-64.

[22]X. Wu, Q. Liang, D. Weng, Z. Lu, The catalytic activity of $\mathrm{CuO}-\mathrm{CeO}_{2}$ mixed oxides for diesel soot oxidation with a NO/O 2 mixture, Catal. Commun. 8 (2007) $2110-2114$.

[23] R. Dziembaj, M. Molenda, M.M. Zaitz, L. Chmielarz, K. Furczoń, Correlation of electrical properties of nanometric copper-doped ceria materials $\left(\mathrm{Ce}_{1-\mathrm{x}} \mathrm{Cu}_{\mathrm{x}} \mathrm{O}_{2-\delta}\right)$ with their catalytic activity in incineration of VOCs, Solid State Ionics 251 (2013) $18-22$.

[24]N.C. Pérez, E.E. Miró, J.M. Zamaro, Cu,Ce/mordenite coatings on FeCrAl- alloy corrugated foils employed as catalytic microreactors for $\mathrm{CO}$ oxidation, Catal. Today 213 (2013) 183-191.

[25]P. Praserthdam, C. Chaisuk, A. Panit, K. Kraiwattanawong, Some aspects about the nature of surface species on Pt-based and MFI-based catalysts for the selective catalytic reduction of NO by propene under lean-burn condition, Appl. Catal. B 38 (2002) 227-241.

[26]G. Qi, R.T. Yang, Selective catalytic oxidation (SCO) of ammonia to nitrogen 
over Fe/ZSM-5 catalysts, Appl. Catal. A 287 (2005) 25-33.

[27]H. Ohtsuka, T. Tabata, O. Okada, L.M. Sabatino, G. Bellussi, A study on selective reduction of $\mathrm{NO}_{x}$ by propane on Co-Beta, Catal. Let. 44 (1997) 265-270.

[28]F. Zhang, P. Wang, J. Koberstein, S. Khalid, S.W. Chan, Cerium oxidation state in ceria nanoparticles studied with X-ray photoelectron spectroscopy and absorption near edge spectroscopy, Surf. Sci. 563 (2004) 74-82.

[29]S. Damyanova, B. Pawelec, K. Arishtirova, M. V. Martinez Huerta, J. L. G. Fierro, Study of the surface and redox properties of ceria-zirconia oxides, Appl. Catal. A: Gen. 337 (2008) 86-96.

[30]J. Guo, D. Wu, L. Zhang, M. Gong, M. Zhao, Y. Chen. J. Preparation of nanometric $\mathrm{CeO}_{2}-\mathrm{ZrO}_{2}-\mathrm{Nd}_{2} \mathrm{O}_{3}$ solid solution and its catalytic performances, Alloys Compd. 460 (2008) 485-490.

[31]J. Fan, X. Wu, L. Yang, D. Weng, The SMSI between supported platinum and $\mathrm{CeO}_{2}-\mathrm{ZrO}_{2}{ }^{-} \mathrm{La}_{2} \mathrm{O}_{3}$ mixed oxides in oxidative atmosphere, Catal. Today 126 (2007) $303-312$.

[32]Q. Wan, L. Duan, K. He, J. Li, Removal of gaseous elemental mercury over $\mathrm{aCeO}_{2}-\mathrm{WO}_{3} / \mathrm{TiO}_{2}$ nanocomposite in simulated coal-fired flue gas, Chem. Eng. J. 170 (2011) 512-517.

[33]H. Li, C. Y. Wu, Y. Li, J. Zhang, $\mathrm{CeO}_{2}-\mathrm{TiO}_{2}$ catalysts for catalytic oxidation of elemental mercury in low-rank coal combustion flue gas, Environ. Sci. Technol. 45 (2011) 7394-7400.

[34]E.Y. Konysheva, S.M. Francis, Identification of surface composition and 
chemical states in composites comprised of phases with fluorite and perovskite structures by X-ray photoelectron spectroscopy, Appl. Surf. Sci. 268(2013) $278-287$.

[35]R. Si, J. Raitano, N. Yia, L. Zhang, S.-W. Chan, M. Flytzani-Stephanopoulos, Structure sensitivity of the low-temperature water-gas shift reaction on $\mathrm{Cu}-\mathrm{CeO}_{2}$ catalysts, Catal. Today 180 (2012) 68-80.

[36]G. Delahay, S. Kieger, N. Tanchoux, P. Trens, B. Coq, Kinetics of the selective catalytic reduction of $\mathrm{NO}$ by $\mathrm{NH}_{3}$ on a $\mathrm{Cu}$-faujasite catalyst, Appl. Catal. B 52 (2004) 251-257.

[37]A. Aboukais, A. Bennani, C. Lamonier-Dulongpont, E. Abi-Aad, G. Wrobel, Redox behaviour of copper (II) species on $\mathrm{CuCe}$ oxide catalysts: electron paramagnetic resonance (EPR) study, Colloids Surf. A 115 (1996) 171-177. 
Table 1. Physico-chemical properties of pure ZSM-5, $\mathrm{Cu}-\mathrm{Z}$ and $\mathrm{CuCe}-\mathrm{Z}$ catalysts.

\begin{tabular}{llll}
\hline Sample & $\begin{array}{l}\text { BET surface area } \\
\left(\mathrm{m}^{2} \mathrm{~g}^{-1}\right)\end{array}$ & $\begin{array}{l}\text { Average pore diameter } \\
(\mathrm{nm})\end{array}$ & $\begin{array}{l}\text { Micro-pore volume } \\
\left(\mathrm{cm}^{3} \mathrm{~g}^{-1}\right)\end{array}$ \\
\hline ZSM-5 & 380 & 2.0 & 0.14 \\
$\mathrm{Cu}-\mathrm{Z}$ & 354 & 1.9 & 0.13 \\
$\mathrm{CuCe} 1-\mathrm{Z}$ & 347 & 1.9 & 0.13 \\
$\mathrm{CuCe} 2-\mathrm{Z}$ & 342 & 1.9 & 0.13 \\
$\mathrm{CuCe} 3-\mathrm{Z}$ & 337 & 1.9 & 0.13 \\
$\mathrm{CuCe} 4-\mathrm{Z}$ & 318 & 1.9 & 0.13 \\
\hline
\end{tabular}


Table 2. Surface composition of $\mathrm{Cu}-\mathrm{Z}$ and $\mathrm{CuCe}-\mathrm{Z}$ catalysts derived from XPS analysis.

\begin{tabular}{|c|c|c|c|c|c|c|c|}
\hline \multirow{2}{*}{ Sample } & \multicolumn{2}{|l|}{$\mathrm{Cu} / \mathrm{Si}$} & \multicolumn{2}{|l|}{$\mathrm{Ce} / \mathrm{Si}$} & \multirow{2}{*}{$\mathrm{Cu}^{+} / \mathrm{Cu}^{2+}$} & \multirow{2}{*}{$\mathrm{Ce}^{3+} / \mathrm{Ce}^{4+}$} & \multirow{2}{*}{$\mathrm{Oo} / \mathrm{Oz}$} \\
\hline & AAS & XPS & AAS & XPS & & & \\
\hline $\mathrm{Cu}-\mathrm{Z}$ & 0.011 & 0.039 & 0 & 0 & 1.142 & I & 0 \\
\hline CuCe1-Z & 0.011 & 0.047 & 0.002 & 0.008 & 0.996 & 0.279 & 0.029 \\
\hline CuCe2-Z & 0.011 & 0.049 & 0.004 & 0.011 & 0.961 & 0.252 & 0.087 \\
\hline CuCe3-Z & 0.011 & 0.058 & 0.006 & 0.024 & 0.867 & 0.246 & 0.178 \\
\hline $\mathrm{CuCe} 4-\mathrm{Z}$ & 0.011 & 0.065 & 0.008 & 0.029 & 0.816 & 0.232 & 0.392 \\
\hline
\end{tabular}


Table 3. Results of hydrogen consumption of pure $\mathrm{ZSM}-5, \mathrm{Cu}-\mathrm{Z}$ and $\mathrm{CuCe}-\mathrm{Z}$ catalysts.

\begin{tabular}{|c|c|c|c|c|c|c|c|c|c|}
\hline \multirow[b]{2}{*}{ Sample } & \multicolumn{2}{|l|}{$\Gamma$} & \multicolumn{2}{|l|}{$\alpha$} & \multicolumn{2}{|l|}{$\beta$} & \multicolumn{2}{|l|}{$\delta$} & \multirow[b]{2}{*}{$\begin{array}{l}\text { Total } \mathrm{H}_{2} \\
\text { consumption } \\
\left(\mu \mathrm{mol} \mathrm{H}_{2} \mathrm{~g}^{-1}\right)\end{array}$} \\
\hline & $\begin{array}{l}\text { Center } \\
\left({ }^{\circ} \mathrm{C}\right)\end{array}$ & $\begin{array}{l}\mathrm{H}_{2} \\
\text { consumption } \\
\left(\mu \mathrm{mol} \mathrm{H}_{2} \mathrm{~g}^{-1}\right)\end{array}$ & $\begin{array}{l}\text { Center } \\
\left({ }^{\circ} \mathrm{C}\right)\end{array}$ & $\begin{array}{l}\mathrm{H}_{2} \\
\text { consumption } \\
\left(\mu \mathrm{mol} \mathrm{H} \mathrm{g}^{-1}\right)\end{array}$ & $\begin{array}{l}\text { Center } \\
\left({ }^{\circ} \mathrm{C}\right)\end{array}$ & $\begin{array}{l}\mathrm{H}_{2} \\
\text { consumption } \\
\left(\mu \mathrm{mol} \mathrm{H} \mathrm{g}^{-1}\right)\end{array}$ & $\begin{array}{l}\text { Center } \\
\left({ }^{\circ} \mathrm{C}\right)\end{array}$ & $\begin{array}{l}\mathrm{H}_{2} \\
\text { consumption } \\
\left(\mu \mathrm{mol} \mathrm{H} \mathrm{g}^{-1}\right)\end{array}$ & \\
\hline $\begin{array}{l}\text { Pure } \\
\text { ZSM-5 }\end{array}$ & - & - & - & - & - & - & - & - & - \\
\hline $\mathrm{Cu}-\mathrm{Z}$ & - & - & 227 & 27 & 280 & 121 & & - & 148 \\
\hline CuCe1-Z & 205 & 16 & 239 & 25 & 277 & 87 & 402 & 49 & 177 \\
\hline $\mathrm{CuCe} 2-\mathrm{Z}$ & 187 & 12 & 220 & 25 & 269 & 79 & 393 & 26 & 142 \\
\hline CuCe3-Z & 201 & 22 & 232 & 57 & 273 & 61 & 370 & 62 & 202 \\
\hline $\mathrm{CuCe} 4-\mathrm{Z}$ & 198 & 36 & 232 & 64 & 270 & 42 & 368 & 22 & 164 \\
\hline
\end{tabular}




\section{Figure Captions}

Fig. 1. Nitrogen adsorption/desorption isotherms of pure $\mathrm{ZSM}-5, \mathrm{Cu}-\mathrm{Z}$ and $\mathrm{CuCe}-\mathrm{Z}$ catalysts: (a) pure ZSM-5; (b) Cu-Z; (c) CuCe1-Z; (d) CuCe2-Z; (e) CuCe3-Z; (f) CuCe4-Z.

Fig. 2. XRD patterns of pure ZSM-5, $\mathrm{Cu}-\mathrm{Z}-5$ and $\mathrm{CuCe}-\mathrm{Z}$ catalysts: (a) pure ZSM-5;

(b) $\mathrm{Cu}-\mathrm{Z}$; (c) CuCe1-Z; (d) CuCe2-Z; (e) CuCe3-Z; (f) CuCe4-Z.

Fig. 3. TEM images of pure ZSM-5 (A), Cu-Z (B) and CuCe4-Z (C) samples.

Fig. 4. Typical XPS narrow spectra $\mathrm{Cu} 2 \mathrm{p}$ from $\mathrm{Cu}-\mathrm{Z}$ (a) and $\mathrm{CuCe} 4-\mathrm{Z}$ (b) catalysts.

Fig. 5. Typical XPS narrow spectra Ce 3d from CuCe4-Z catalysts.

Fig. 6. Typical XPS narrow spectra $\mathrm{O}$ 1s from $\mathrm{Cu}-\mathrm{Z}$ (a) and $\mathrm{CuCe} 4-\mathrm{Z}$ (b) catalysts.

Fig. 7. $\mathrm{NH}_{3}-\mathrm{TPD}$ curves of pure $\mathrm{ZSM}-5$ (a), Cu-Z (b), CuCe1-Z (c), CuCe2-Z (d), CuCe3-Z (e) and CuZr-Z (f) catalysts.

Fig. 8. $\mathrm{H}_{2}-\mathrm{TPR}$ curves of pure $\mathrm{ZSM}-5$ (a), Cu-Z (b), CuCe1-Z (c), CuCe2-Z (d), CuCe3-Z (e) and CuZr-Z (f) catalysts.

Fig. 9. Catalytic activities for $\mathrm{NO}$ reduction by $\mathrm{NH}_{3}$ for pure $\mathrm{ZSM}-5, \mathrm{Cu}-\mathrm{Z}, \mathrm{CuCe} 1-\mathrm{Z}$, CuCe2-Z, CuCe3-Z and CuZr-Z catalysts. 


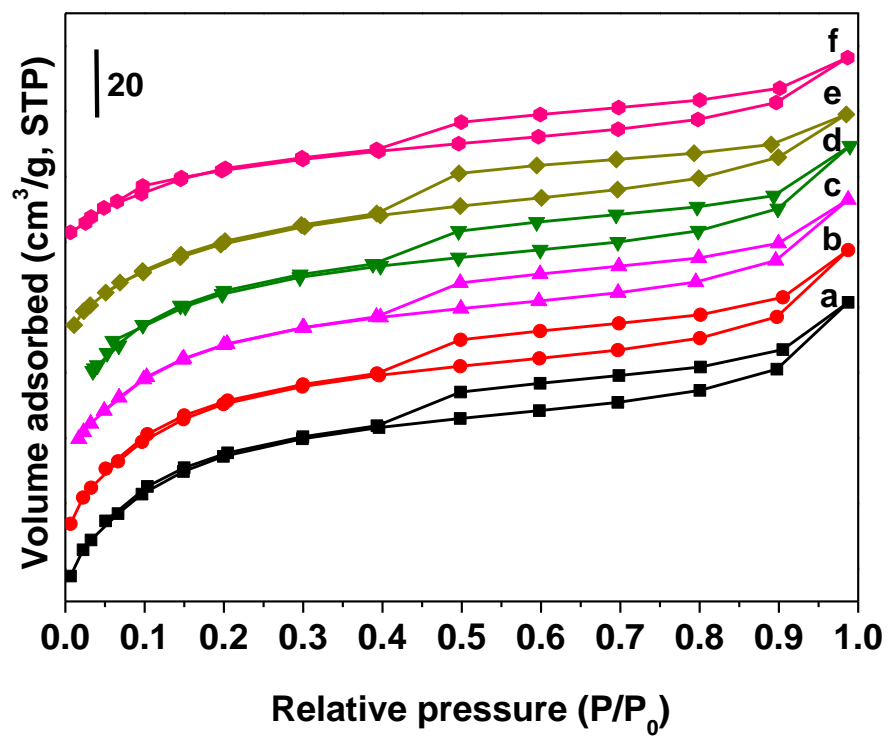

Fig. 1. 


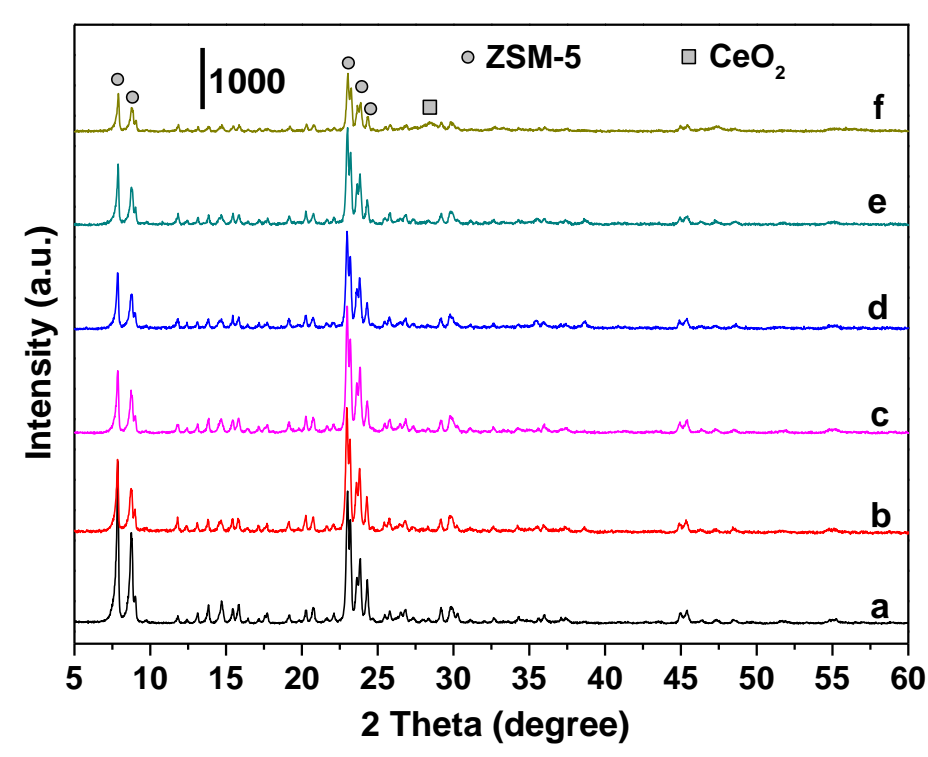

Fig. 2. 

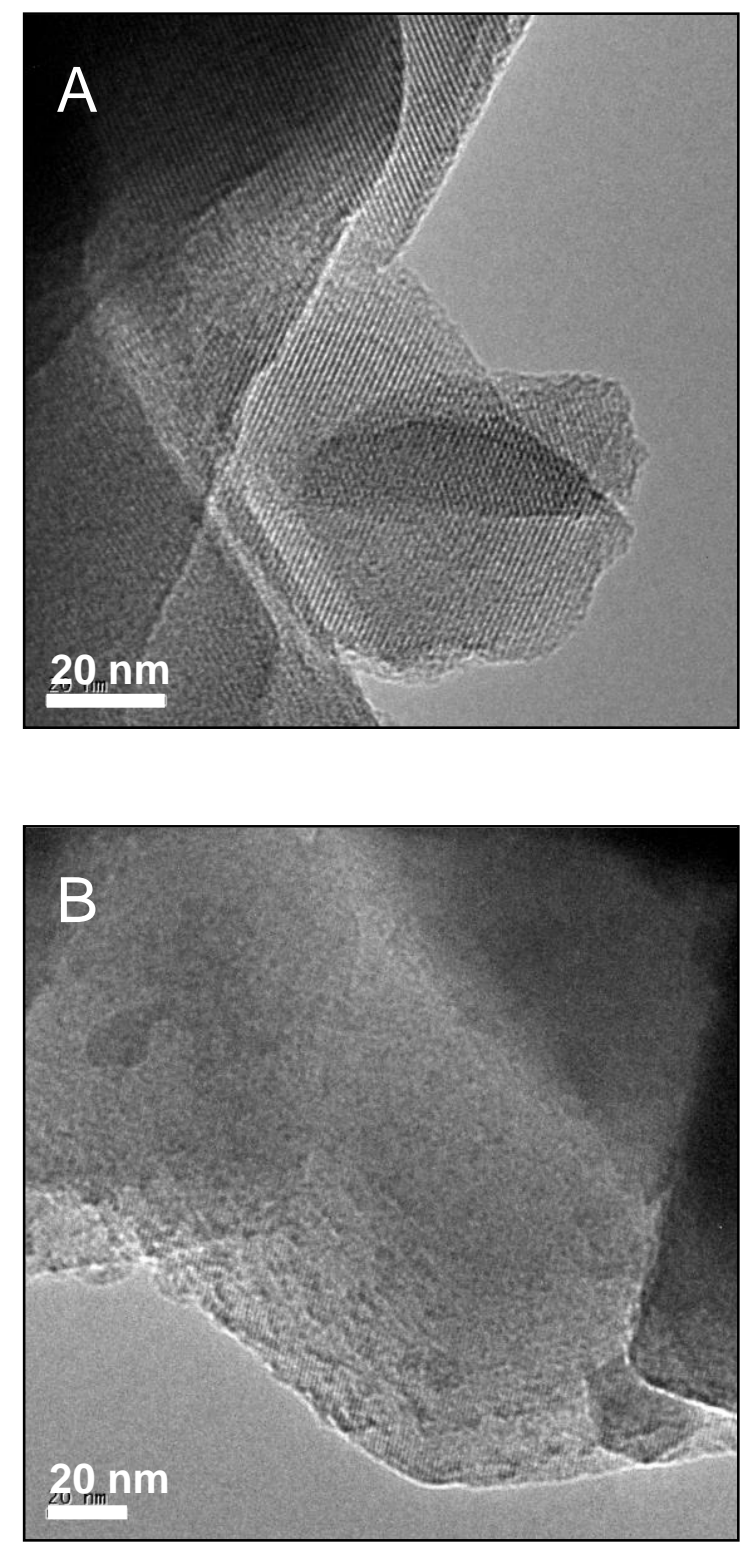


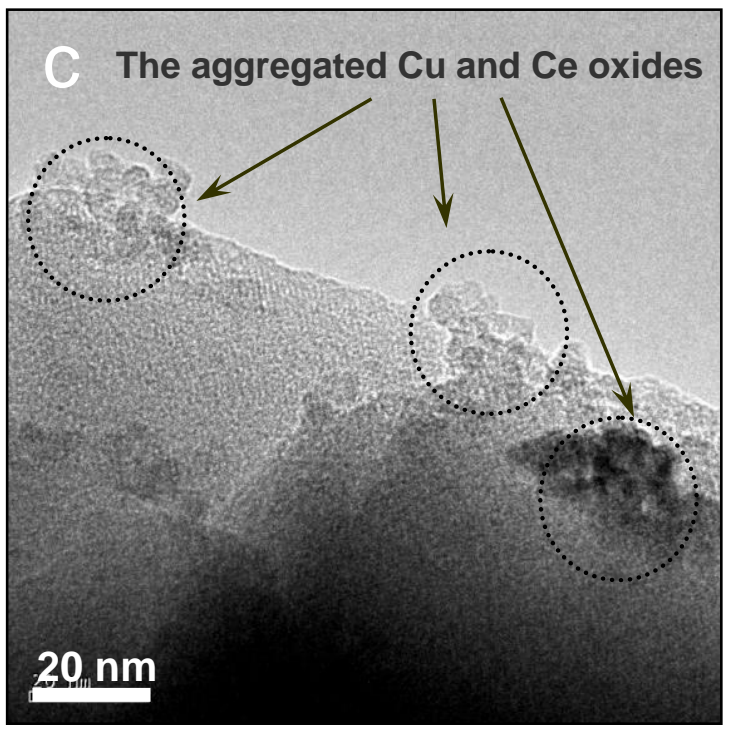

Fig. 3.

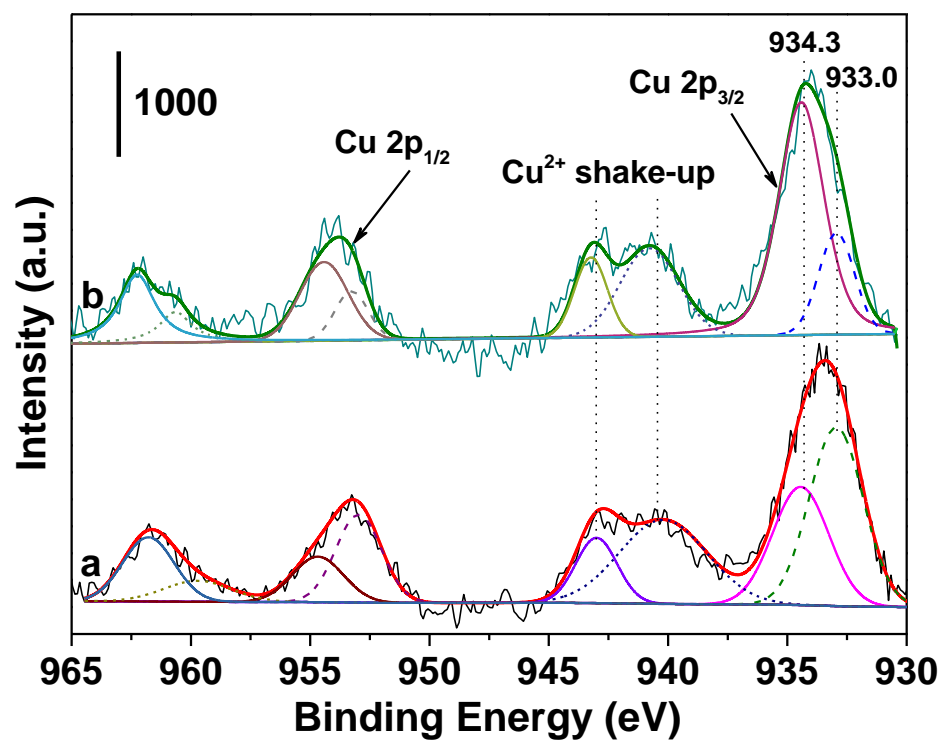

Fig. 4. 


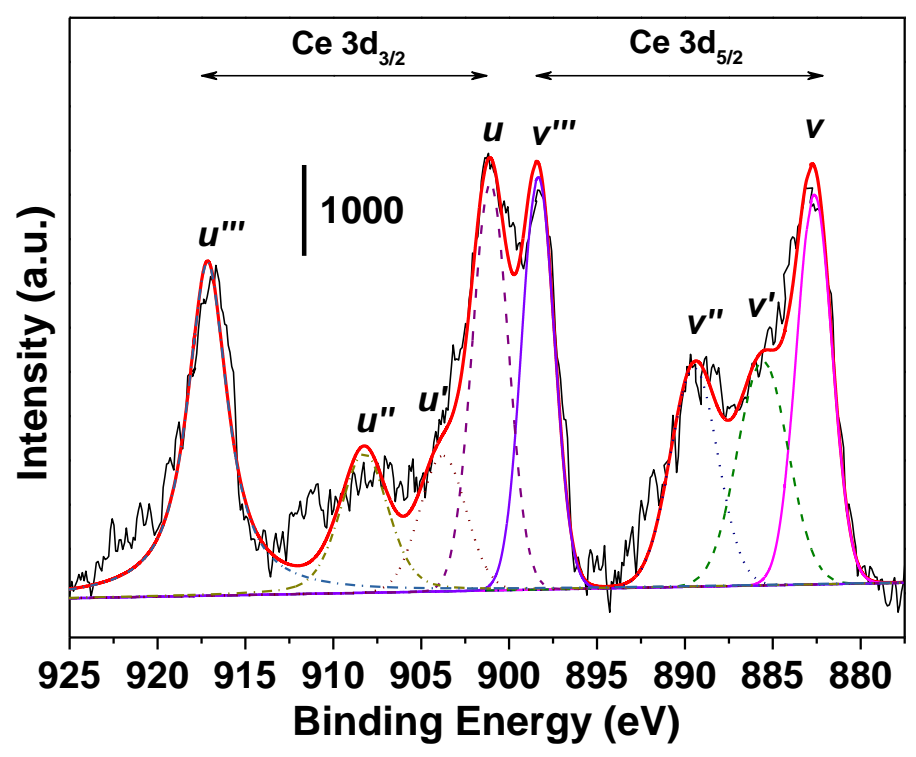

Fig. 5. 


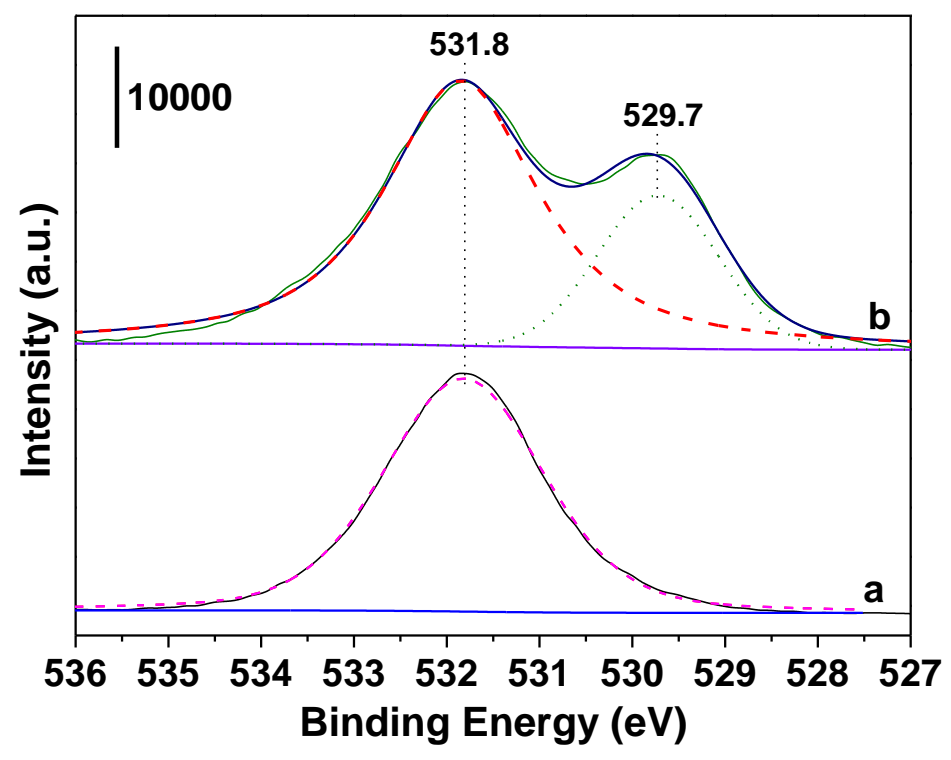

Fig. 6. 


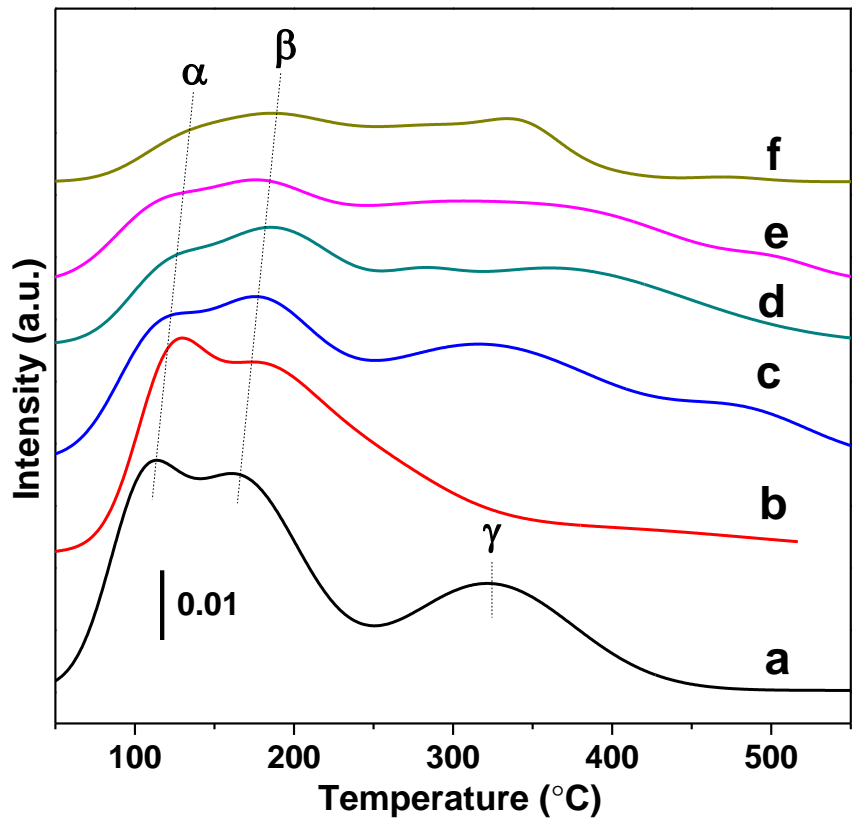

Fig. 7. 


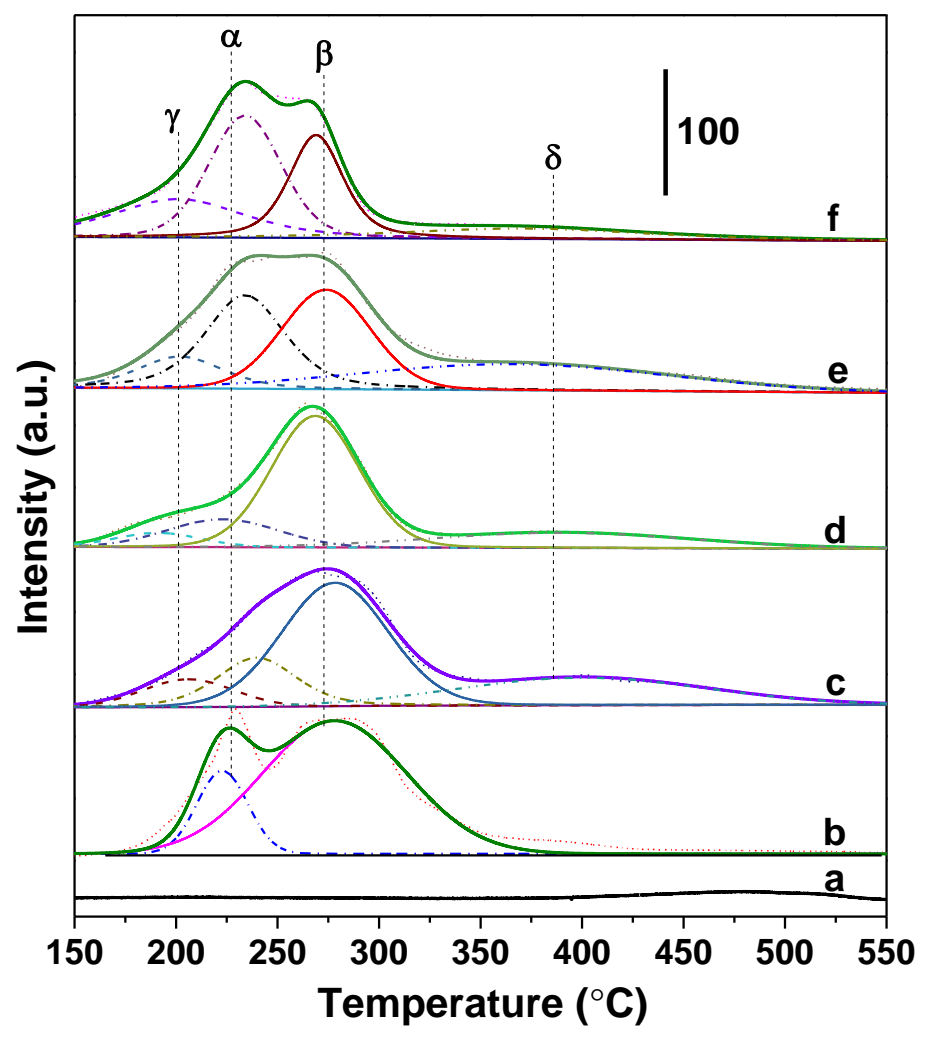

Fig. 8. 


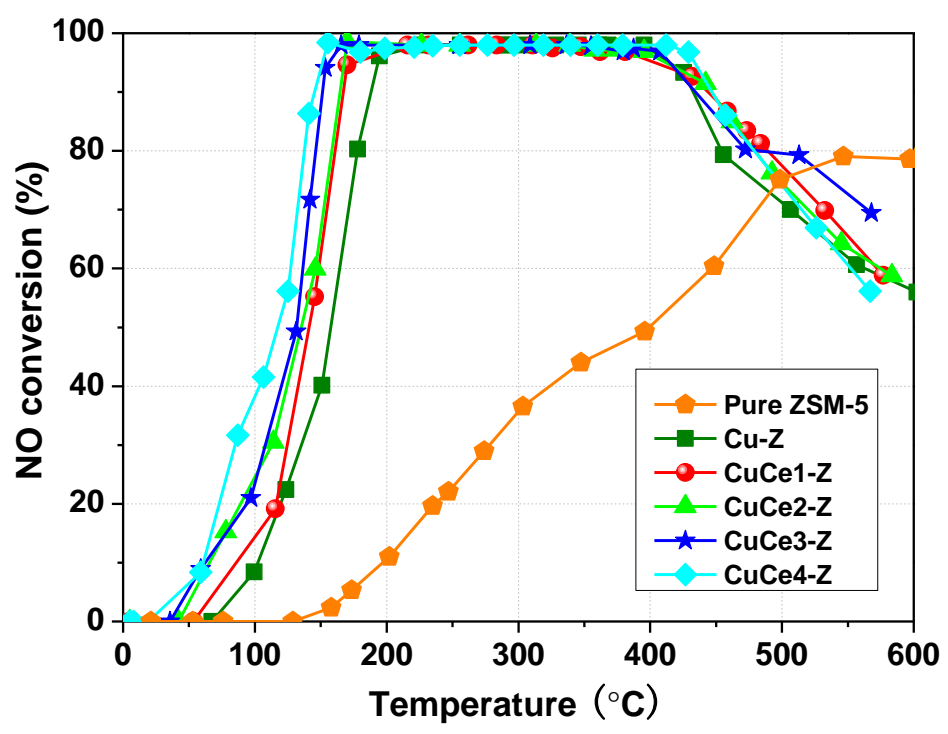

Fig. 9. 